\title{
CFD Simulation of Hydrodynamic and Thermal Performance of a Micro Heat Exchanger
}

\author{
W. Nastoll and C. Boyer \\ IFP Energies nouvelles-Lyon, Rond-point de l'échangeur de Solaize, BP 3, 69360 Solaize - France \\ e-mail: willi.nastoll@ifpenergiesnouvelles.fr - christophe.boyer@ifpenergiesnouvelles.fr
}

\begin{abstract}
Résumé - Simulation numérique par CFD de l'hydrodynamique et des performances thermiques d'un micro échangeur de chaleur - Pour évaluer les performances et les limitations d'un échangeur thermique compact composé de plaques micro-structurées, des simulations CFD de l'hydrodynamique et des transferts thermiques ont été effectués en écoulement liquide/liquide pour un micro-échangeur commercialisé par l'IMM. Les résultats de la simulation hydrodynamique montrent que la distribution des flux de l'écoulement liquide est plutôt homogène avec quelques gradients de vitesses à l'entrée des canaux à cause d'effets inertiels dans le distributeur. Les profils de température sont influencés à la fois par les transferts thermiques par convection dans les canaux et dans les zones de distribution et de collecte de l'écoulement et également par les transferts par conduction aux travers des parois métalliques situées entre les canaux et à la périphérie de la zone micro-structurée, en particulier pour les faibles débits liquides. À cause de ces transferts de chaleur parasites, la fraction du flux thermique qui est réellement transférée au travers des micro-canaux varie entre 75 et $85 \%$ du flux thermique total en écoulement contre-courant et entre 35 et $70 \%$ en écoulement co-courant. Les résultats des simulations numériques sont en bon accord avec les profils de température mesurés au sein du micro-échangeur.
\end{abstract}

\footnotetext{
Abstract - CFD Simulation of Hydrodynamic and Thermal Performance of a Micro Heat ExchangerTo evaluate the performances and limitations of compact heat exchanger with micro-structured plates, CFD simulations of hydrodynamics and thermal transfers have been performed inside a commercial micro heat exchanger from IMM operated in liquid/liquid flows. The hydrodynamic results show that the flow rate distribution over the plates is rather homogeneous with some velocity gradient at the channel inlet due to inertial effect in the distributor. Fluid temperature profiles are both influenced by convective transfer in the channels and in the distributing/collecting sections and by conductive transfer through the metal wall at the plate periphery especially at low flow rates. Due to undesired heat transfer by conduction, the fraction of heat power really transferred inside the channels varies from 75 to $85 \%$ in counter current flow configuration and between 35 and $70 \%$ in co-current flow configuration. Computational results are successfully compared to $2 D$ experimental temperature profiles measured inside the heat exchanger.
} 


\section{INTRODUCTION}

Process intensification will play a key role in the development of efficient chemical processes with reduced effect on environment in the future. In this context, new tools such as micro-structured reactors or heat exchangers can be used to better control reaction conditions and to optimize heat transfer and thus reaction temperature control in a smaller volume. Such systems can be used, for instance, to intensify heat integration in an hydrogen generator at small capacity to perform feed vaporizing or heat recovery between synthesized gas and process feed, water and oxidant gas.

In micro-structured heat exchangers, heat transfer is enhanced both by heat conductance increase and by interfacial area (transfer area by heat exchanger volume) intensification. The heat conductance on flow side is increased since heat conduction occurs through very low channel hydraulic diameter. In order to provide new correlations for the heat coefficient in convection mode, several authors have performed experimental studies with one or few parallel micro-channels (Peng and Peterson, 1996; Yu et al., 1991; You, 1989; Favre-Marinet et al., 2003; Halbritter et al., 2002). Due to the high fraction of solid wall inside micro-structured heat exchanger, the heat conduction inside the wall can take a non negligible part to the whole heat transfer inside the heat exchanger. Maranzana et al. (2004) have studied the influence of axial heat conduction in the wall by 3D simulation of the thermal flux around one or two micro-channels. When the heat conduction through the walls is taken into account, they were able to measure the convective heat coefficient inside the channel and the corresponding Nusselt number were in accordance with classical correlations for the laminar flow inside the channels. If a 1D model is used, the convective heat transfer coefficient is under estimated due to the heat conduction in the wall that lead to reduced temperature difference between hot and cold side at channels inlet and outlet.

Another multidimensional simulation has been performed by Gamrat et al. (2004) to interpret experimental results obtained in convective heat transfer inside a $2 \mathrm{D}$ channel by Favre-Marinet et al. (2003). The simulation takes into account heat conduction in the walls and the inlet effects inducing a thermal flow profile establishment that impacts on heat transfer. In this case, the flow simulation did not achieve to explain the decrease of heat transfer coefficient within channel height at low Reynolds number. Some work has also been devoted to flow simulation by CFD codes inside microreactor to analyze flow distribution between a series of parallel micro-channels (Niklas and Favre-Marinet, 2003; Tonomura et al., 2003) but the heat flux has not been simulated.

In order to further understand and quantify the heat flux and heat transfer performances inside a whole heat exchanger with a network of micro-channels and distribution/collecting sections, an experimental study has been performed at IFP-Lyon with a micro heat exchanger from IMM (Font $e t$ al., 2006). Pressure drops and temperatures were measured for the two flow circuits during convective transfer tests with hot and cold water flows. Heat transfer global performances have been evaluated by temperature gradient measurement between hot and cold side at inlets and outlets in co and counter current flows. Finally temperature profiles have been measured in 2D across the channels network. This kind of characterization is quite new and generally not done for a complete exchanger and in particular with a network of microchannels since it is very difficult to get local information inside the channels. The experimental data showed that for low liquid flow rates thermal profiles are not homogenous across the micro structure plate width and that in some configuration a large amount of heat transfer takes place inside the distributing and collecting sections.

To interpret the experimental data, a first 3D simulation (in Fortran) was performed to estimate the temperature profiles due to the heat flux by convection inside the channels and by conduction through the walls between channels. Nevertheless, since the distributing and collecting section were not included due to mesh complexity, it was not possible to estimate the role of these sections on flow distribution and heat transfer efficiency. Thus it has been decided to perform CFD calculations in 3D using the commercial Fluent code to simulate the flow distribution inside the whole open volume of micro-structured plates and the different heat exchange flux through the whole heat exchanger structure in liquid/liquid flow convective mode. The objective was both to check that such computational fluid dynamics code with classical turbulent models can still be used for very small channel hydraulic diameters and to explain why the high heat transfer performances obtained in micro-channels can be masked by other heat transfers through the whole metallic structure and in the distributor/collector zones.

\section{DESCRIPTION OF MICRO HEAT EXCHANGER AND EXPERIMENTAL PROTOCOL}

\subsection{Geometry and Sizes of Micro Heat Exchanger}

The micro heat exchanger selected is developed by IMM and called COMH Counter Flow Micro Heat Exchanger (see Fig. 1a). It is composed of a series of parallel microstructured plates that can be easily added or removed (see Fig. 1b). The number of plates can thus varies from 2 to 18 in order to investigate a large range of Reynolds number inside micro-channels. For each flow circuit, the inlet and outlet orifices are located on opposite sides with respect to the plate symmetry axis and these positions are inverted from hot plate to cold plate. The cold and hot flows can be co-current or counter current. An example of flow circulation of cold and hot fluids in co-current flow is presented in 


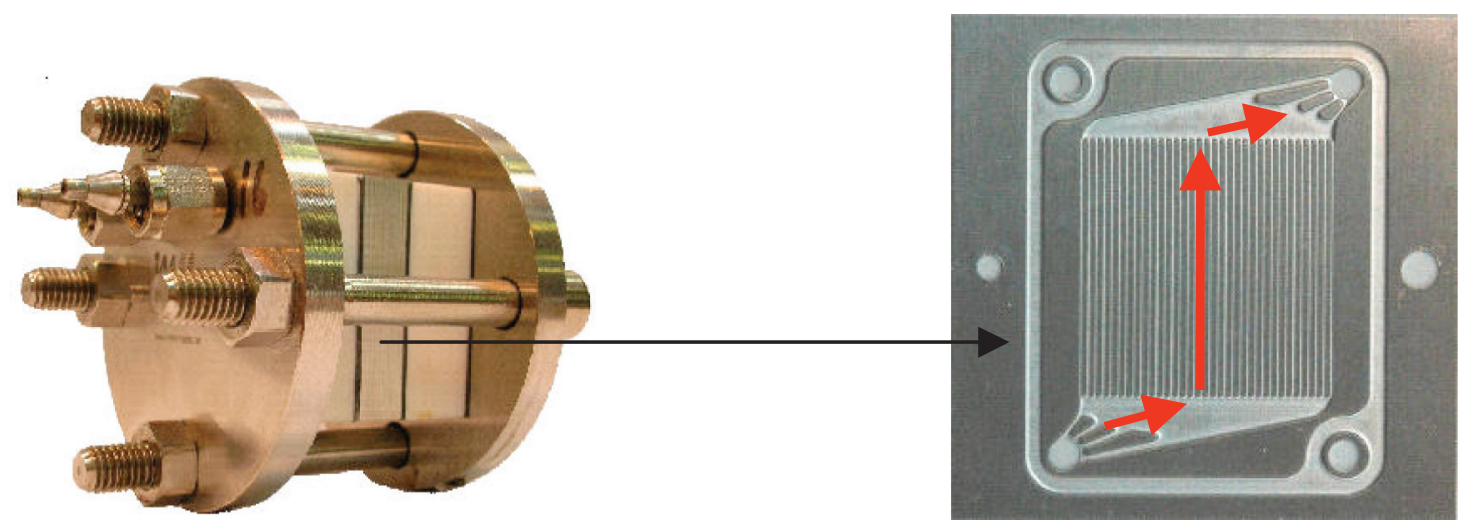

a)

b)

Figure 1

Image of: a) micro heat exchanger $\mathrm{COMH}, \mathrm{b}$ ) structured plate with the fluid flow direction.

Figure 2. The main sizes of plate and micro-channels are described in Tables 1 and 2 respectively. A graphite gasket is inserted at the periphery of plates and around inlet/outlet orifices to avoid any fluid leakage. Two insulation plates in glass-ceramics are added at the two extremities of the heat exchanger to avoid thermal losses.

TABLE 1

Sizes of micro-structured plates

\begin{tabular}{c|c|c}
\hline Parameter & Unit & Micro-structured plate \\
\hline Number & & 2 to 18 \\
\hline Length & $\mathrm{mm}$ & 40 \\
\hline Width & $\mathrm{mm}$ & 40 \\
\hline Height & $\mu \mathrm{m}$ & 560 \\
\hline
\end{tabular}

TABLE 2

Sizes of micro-channels

\begin{tabular}{c|c|c}
\hline Parameter & Unit & Micro-channels \\
\hline Number & & 34 \\
\hline Length & $\mathrm{mm}$ & 20 \\
\hline Width & $\mu \mathrm{m}$ & 260 \\
\hline Height & $\mu \mathrm{m}$ & 160 \\
\hline Thickness between channels & $\mu \mathrm{m}$ & 320 \\
\hline
\end{tabular}

\subsection{Experimental Protocol}

To determine the temperature profile inside the channels, a plate has been added between two successive microstructured plates. This plate is $1 \mathrm{~mm}$ thick and 4 circular wells of $0.5 \mathrm{~mm}$ in diameter are drilled within the plate thickness to insert thermocouples. This plate is oriented in order to have the thermocouples parallel to the microchannels of heat exchanger. The thermocouples wells are located on both sides of the symmetrical axis of structured plates at a distance respectively of 2.45 and $7.85 \mathrm{~mm}$ from this axis. Each thermocouple well is located in front of a single channel and a part of its walls. The thermocouples were positioned within these wells at five different equally spaced axial locations from channel inlet to outlet. These positions were determined with an uncertainty of about $+/-0.5 \mathrm{~mm}$. Three configuration are then implemented in order to detect the temperature profile on the cold side, on the hot side and in the wall between cold and hot sides. In all cases the heat exchange between one single cold plate and one single hot plate is studied. To determine the temperatures on the cold side, the measurement plate is inserted between two cold plates each exchanging with one hot plate (configuration 1, Fig. 2a). The temperature profiles in the plates on both sides of the measurement plate are assumed to be identical since the heat losses through the circular channel connecting the plates induces a very low temperature difference (estimated to be lower than $0.07^{\circ} \mathrm{C}$ ) between inlet temperatures of two successive cold or hot plates. The system being totally symmetrical, the two cold plates undergo the same temperature profile, thus no thermal flux should happen between themselves. The temperatures measured inside the added plate are wall temperatures that are therefore representative of the cold flow. The same protocol is used to measure the temperatures on the hot flow side (configuration 2, Fig. 2b). To measure the temperatures inside the wall, the added plate can be simply inserted between one cold and one hot plate (configuration 3, Fig. 2c). For each configuration, the temperatures are measured following 5 
a)

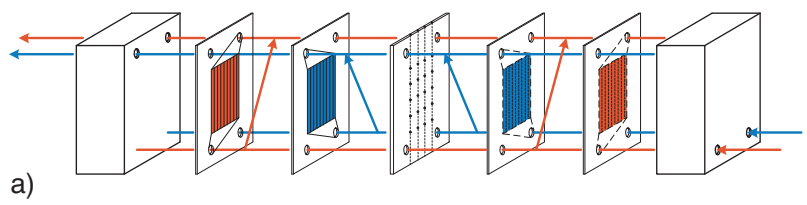

b)

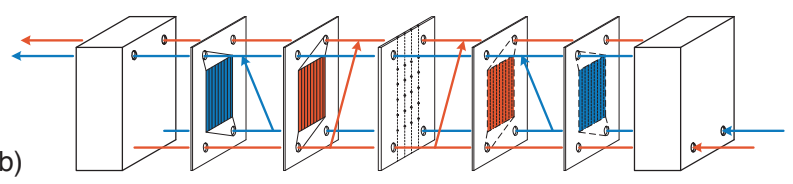

c)

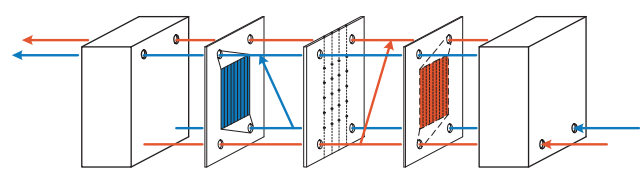

Figure 2

Heat exchanger geometry end flow circulation scheme to measure 2D temperature profile: a) on hot side (configuration $1)$, b) on cold side (configuration 2); and c) on the wall between hot and cold side (configuration 3 ).

different axial position by progressively moving the thermocouples inside the wells. A map of 20 temperature data is thus obtain in 2D for each plate and for the intermediate wall. The whole data are presented and commented in Font et al. (2006).

\section{CFD MODELING DESCRIPTION}

\subsection{Geometry and Meshing}

Following the modularity of the heat exchanger, the microstructured plates were meshed individually using about 1.7 million tetrahedral and hexahedral cells. $60 \%$ of the cells describe the fluid zones i.e. the distributing/collecting sections and the micro-channels, the remaining fraction of cells was integrated in two solid zones representing the metal plate and the graphite gasket. In particular, a micro channel has a total of 6200 cubic cells and its cross section is meshed with 31 cells (between 7 and 8 cells along channel width and 4 cells along channel depth) which provide a good spatial resolution for the modeling of the laminar flow (maximal Reynolds Number $R e_{\max }=250$ ) inside channels. In all simulations the heat exchange between two micro-plates were evaluated using two meshes connected via nonconformal interfaces resulting in a total of over 3.4 million cells. The plate used in the experiments to introduce the thermocouples was not simulated. The simulated geometry correspond thus to configuration 3 without intermediate plate for thermocouples insertion. The thermal profile inside the whole heat exchanger with several plates in parallel has not been simulated due to meshing capacity limitations.

\subsection{Resolution and Boundary Conditions}

The 3D Navier-Stokes equations were solved for steady incompressible laminar flow with heat transfer using the double precision version of commercial code FLUENT6.2. The following options were selected:

- segregated implicit solver, SIMPLE scheme for the pressure-velocity coupling;

- second order discretization scheme for all variables;

- standard under-relaxation factors.

For all external surfaces, natural convection with air at ambient temperature was taken as thermal boundary condition. For the surface in contact with the glass-ceramic insulation plate, the thin-wall thermal resistance model (solving a 1D conduction equation to evaluate the effect of the insulation) was used, whereas the surface in contact with the thermocouple plate was adiabatic for the configurations 1 and 2 (Fig. 2). Mass-flow-inlet and pressure-outlet were used for the flow boundary conditions. All calculations were performed until a convergence level well below the standard Fluent convergence criteria has been reached and the conservation of mass and energy has been checked. The solving time on a 16 processor linux-cluster was less than one day.

\section{CFD RESULTS}

\subsection{Hydrodynamic Results}

The flow distribution efficiency has been first evaluated by deducing from CFD results the profiles of cross section averaged velocity at channel inlet for the 34 parallel channels (Fig. 3). The distribution section design appears to be optimized for a medium flow rate of about $2 \mathrm{~L} / \mathrm{h}$. At this flow rate, the flow distribution is almost homogeneous over the channels. At higher flow rates the averaged flow velocity in the channels appears to be higher near the distributor entrance with a rapid decrease and a progressive increase when the distance from the plate entrance increases. The inertial effect at the slit outlets in the distributor entrance induces preferential flow in the neighbouring channels. Then, for the following channels, the tangential flow velocity induced by the entrance slits is higher than the axial velocity creating an underflow in the channels that decreases when tangential flow velocity in the distributor decreases. At lower flow rates, the inertial effect in the distributor is much lower and the opposite effect occurs with a gradual decrease of flow velocity in the channels with increasing distance from the distributor entrance. Nevertheless the observed deviations 


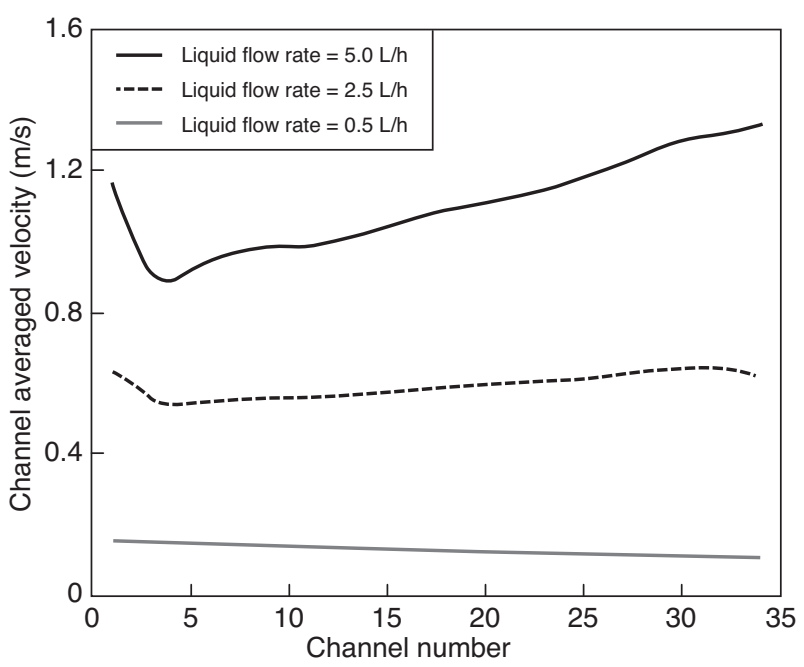

Figure 3

Cross section averaged velocity inside the micro-channels as a function of liquid flow rate.

remain moderate with a standard deviation corresponding to about $10 \%$ of mean velocity for the extreme flow rates.

\subsection{Temperature Profiles}

The simulated thermal profiles have been first compared to temperature data measured in 20 different positions inside the heat exchanger by moving thermocouples in a drilled plate between two adjacent hot or cold plates (Fig. 4). Four thermocouples (T1 to T4) are moved along channels axis following 4 different channels equally spaced along the plate width. The uncertainties on temperature were quantified and were lower than $+/-0.5^{\circ} \mathrm{C}$ for the four thermocouples. The calculated axial temperature profiles follow the measured values. The slight radial differences in the transverse direction, observed between channels, is also well reproduced. For counter current flow, the cross over of the temperature profiles is predicted but the slop is slightly different. In general way, the simulations underestimate the measured temperature but the difference between calculated and predicted value remain moderate in the channel section, the mean difference is $-2.8^{\circ} \mathrm{C}$ for co-current date and $-1.5^{\circ} \mathrm{C}$ for counter-current data. These small difference can come from the uncertainty of the thermocouple axial position $(+/-0.5 \mathrm{~mm})$ on experimental side but can also come from the uncertainty on material heat conductivity values used for the calculation. A larger temperature difference of $15^{\circ} \mathrm{C}$ appears at the point corresponding to the frontier between distribution zone and channel entrance but since the simulated temperature increase is very sharp, a comparison with a single measurement point is likely to be imprecise.
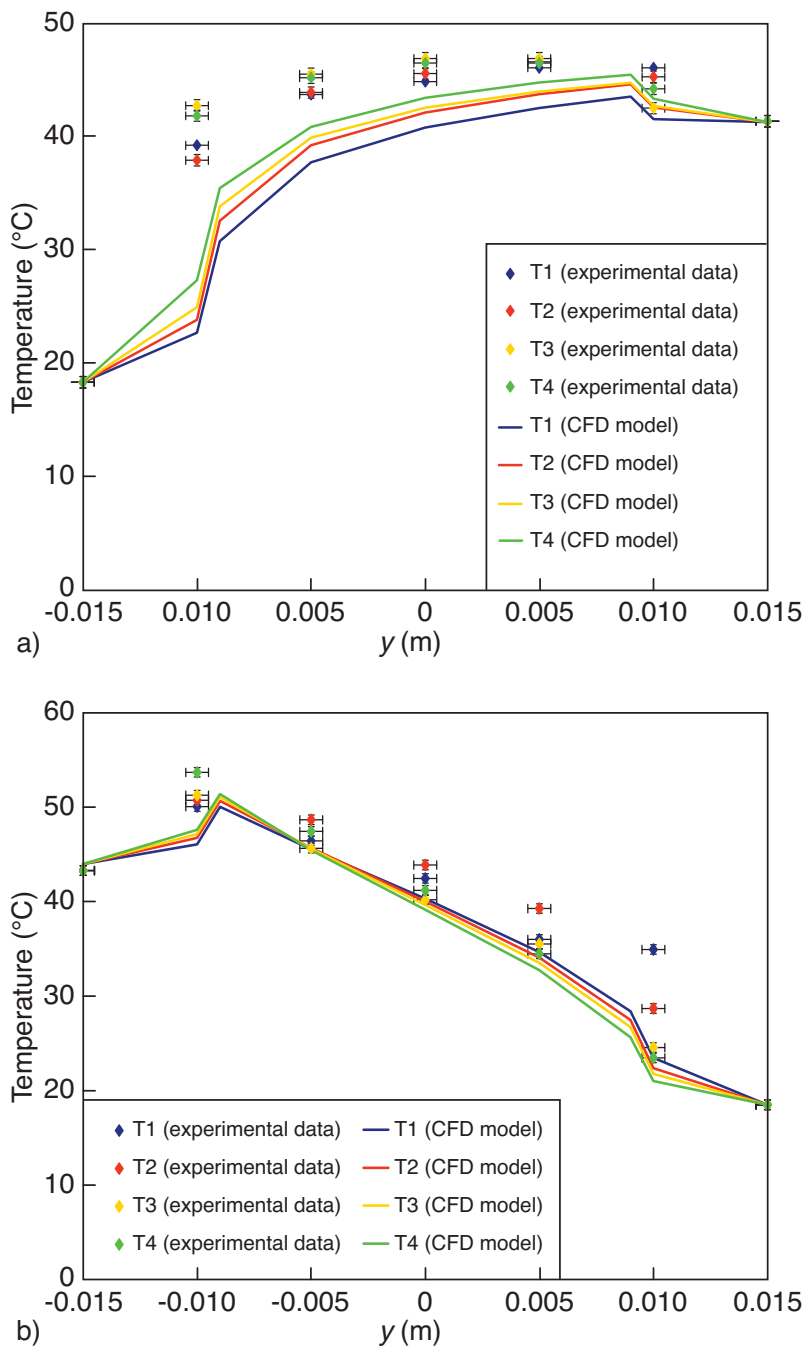

Figure 4

Comparison of experimental and calculated temperature profiles over the plate axial direction for liquid flow rate of $5 \mathrm{~L} / \mathrm{h}$ : a) co-current flow configuration, b) counter-current flow configuration.

With co-current flow configuration, hot inlet/outlet and cold inlet/outlet are on the same side with respect to the plate symmetry axis, dividing the plate in a hot section at the left side of plate and a cold side at the right. The heat transfer through the metallic wall induces thus an horizontal temperature profile through the plate (Fig. 5). In this configuration, the thermal gradient being orthogonal to the channel direction, the heat exchange mainly occurs in the distributing and collecting section where the flow is perpendicular to the channel flow. The heat exchange in the channel is therefore much more reduced. This impact of the heat conduction in the metallic structure on the overall heat exchange decreases when heat transfer by convection is enhanced with flow rate 


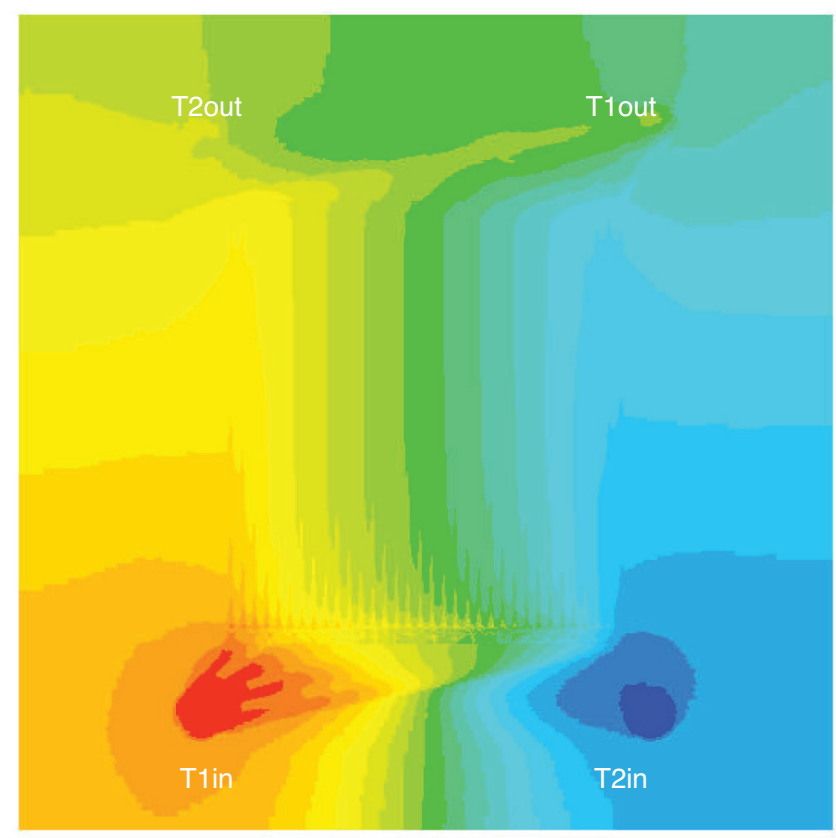

a)

Figure 5

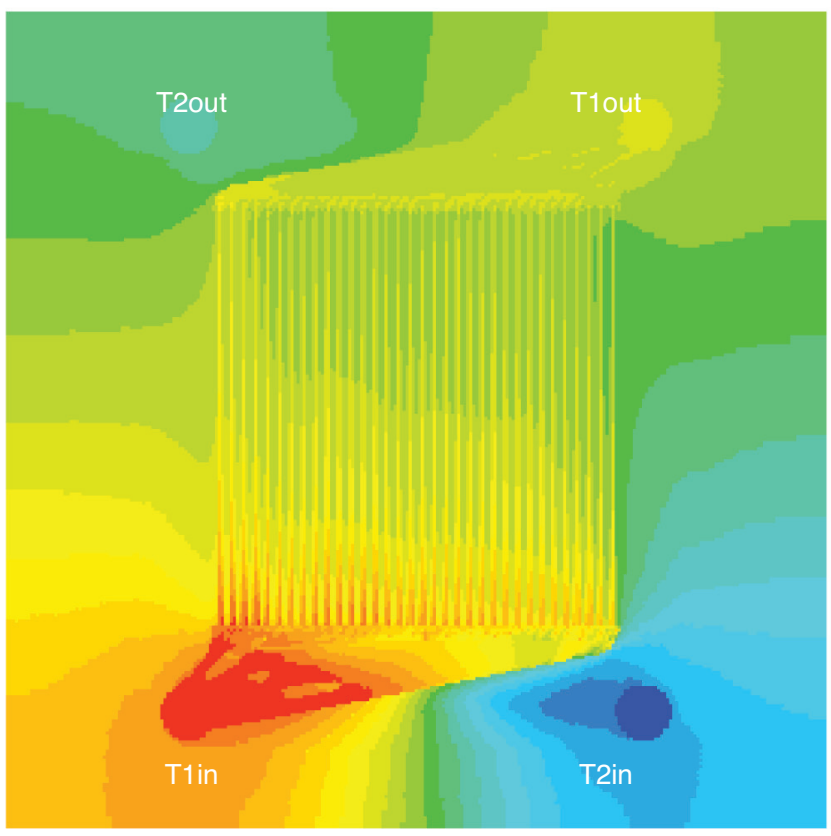

b)

Calculated temperature profiles of one micro-structured plate with co-current flow: a) liquid flow rate: $0.5 \mathrm{~L} / \mathrm{h}, \mathrm{b})$ liquid flow rate: $5 \mathrm{~L} / \mathrm{h}$.
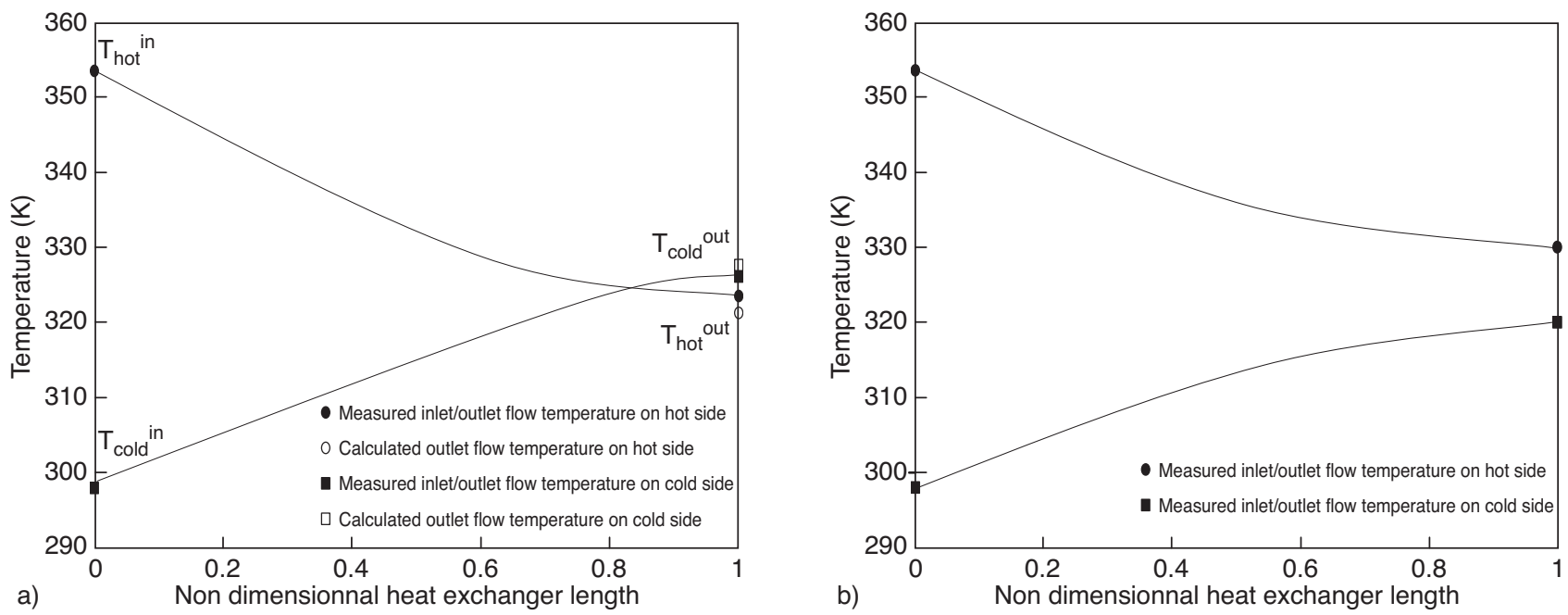

Figure 6

Experimentally observed and simulated temperature profiles for co-current flow for a liquid flow rate of a) $0.5 \mathrm{~L} / \mathrm{h}$, and b) $5 \mathrm{~L} / \mathrm{h}$.

increase (Fig. 5b). At low flow rates, due to the dominant effect of heat conduction through the wall (at the plate periphery) the hot side outlet temperature is highly influenced by the cold side inlet temperature (and vice-versus for cold side outlet temperature). This results in an outlet temperature on the hot side being lower than the outlet temperature on the cold side (Fig. 6a). This phenomenon experimentally observed is unexpected in theoretical co-current thermal exchange (Fig. 6b) since in a standard co-current heat exchanger the outlet cold fluid cannot be more hot than the outlet hot fluid. The calculations clearly explain this observation. The heat flux though the metal plate on the left hand side of the heat exchanger contributes to the direct heat transfer from hot inlet towards the cold outlet. In the same way, 


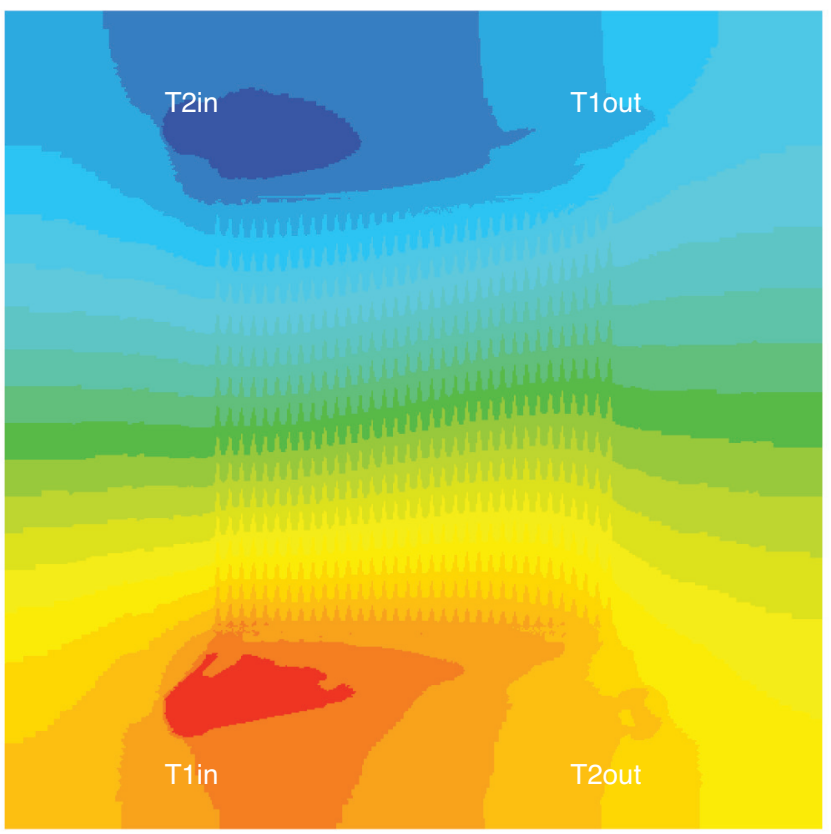

a)

Figure 7

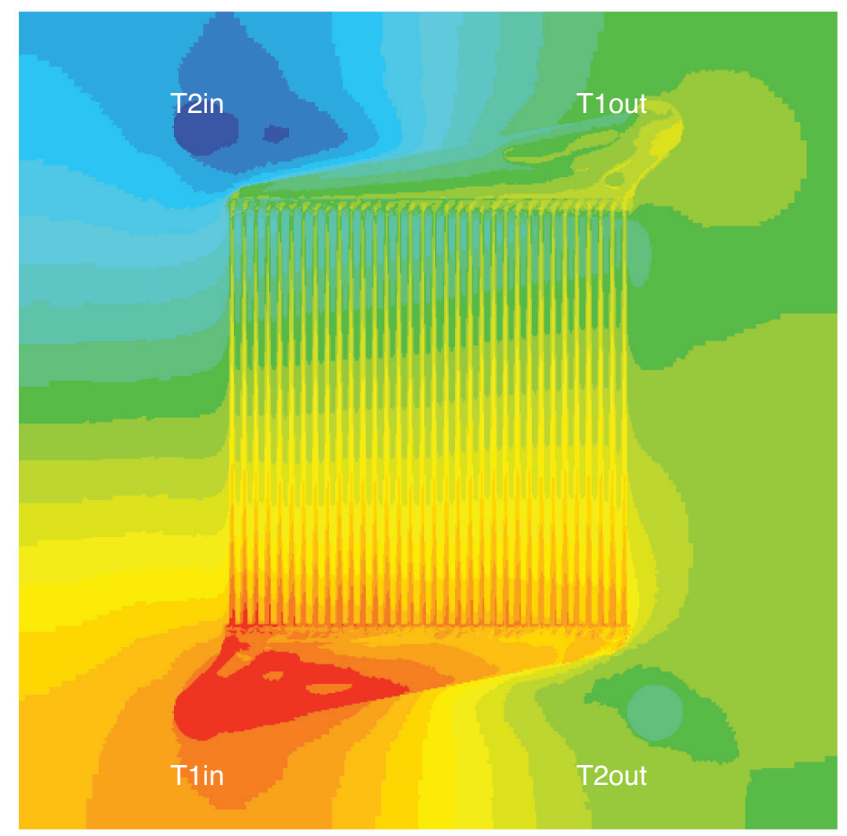

b)

Calculated temperature profiles of one micro-structured plate with counter current flow: a) liquid flow rate: $0.5 \mathrm{~L} / \mathrm{h}, \mathrm{b}$ ) liquid flow rate: $5 \mathrm{~L} / \mathrm{h}$.

the heat flux though the metal plate on the right hand side of the heat exchanger contributes to the direct heat transfer from cold inlet towards the hot outlet.

In the counter current flow configuration, the temperature profiles are mainly longitudinal following the micro-channels axis (Fig. 7). At low flow rate (Fig. 7a), the temperature profile are the same in the channels flow and the walls due to dominant effect of heat conduction. At higher flow rate (Fig. 7b), the flow convection drives the heat transfer inside the channels and the distributing/collecting sections. In this case, the temperature profiles are rather homogeneous between channels and differ from temperature profiles in the surrounding wall at the periphery of plates.

The fraction of heat flux really exchanged in the microchannels has been estimated by the ratio of the heat power exchanged between channel inlet and outlet (from channel inlet/outlet temperatures) and the total heat power exchanged between heat exchanger inlet and outlet (from heat exchanger inlet/outlet temperatures). As one can see in Figure 8, the fraction of total heat flux really exchanged in the channel section is quite different between flow configurations. In cocurrent flow configuration, the fraction of heat flux within the micro-channels over total heat flux varies from $30 \%$ to $70 \%$ with increasing flow rate. At low flow rate a large part of heat exchange takes places in distributor and collector, that are non micro-structured, due to heat conduction in the wall and geometric position of flow inlets and outlets. When the flow rates increase, the effect of convective heat transfer inside channels becomes predominant and the fraction of heat exchange through the channels tends to $70 \%$. In the counter-current flow configuration, the micro-channels

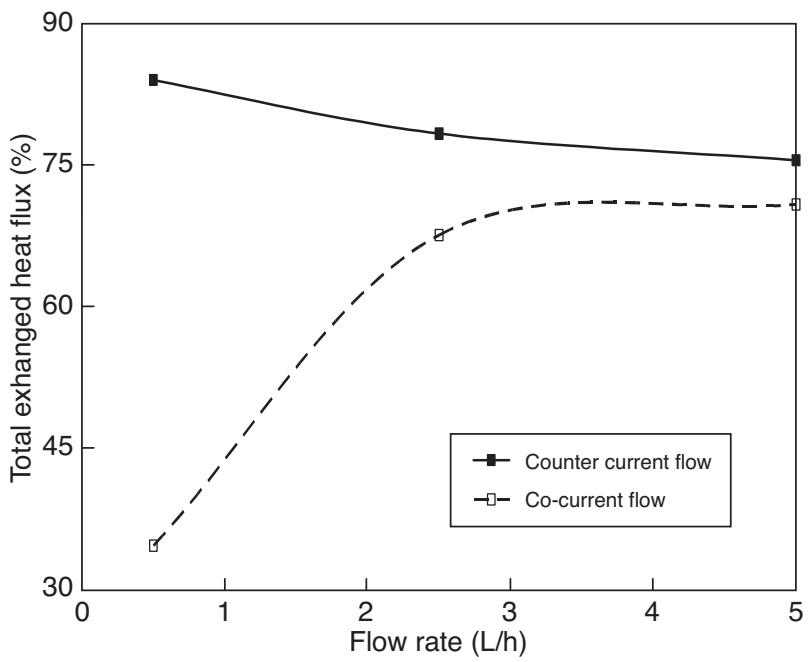

Figure 8

Fraction of total heat flux really exchanged inside the microchannels section as a function of liquid volume flow rate. 
always contribute to more than $75 \%$ of the total exchanged heat flux. Nevertheless, this fraction decreases from about 85 to $75 \%$ with flow rate. As a matter of fact, at low flow rate in counter flow configuration, the temperature profile in the distributor and collector is more flat since heat conduction in the wall between hot distributor and cold collector occurs with a very low temperature difference.

It has not been possible to study the effect of variation of number of plates on thermal profiles due to meshing limitations. Nevertheless, experimental data have shown that the variation of global heat conductance with the number of plates is not very large for same channel Reynolds values. The global heat conductance was increased when the number of plates is increases due to reduced impact of heat transfer at heat exchanger periphery but differences are lower than $10 \%$ for $R e>200$.

\section{CONCLUSIONS}

Hydrodynamics and thermal profiles have been estimated in a microstructured heat exchanger by CFD modelling using the commercial Fluent code. Some moderate deviation appears in the flow distribution between channels due to inertial effect at plate entrance and due to competition between tangential flow velocity in the distributor and axial flow in the channels. The temperature profiles estimated by CFD are in a good agreement with measured ones in 2D inside the heat exchanger. The temperature variation along axial and transverse direction (between channels) are correctly predicted. The simulation of heat exchange through the entire heat exchanger including heat conduction in the wall exhibits strong differences in the thermal exchange efficiency through the micro-channels between co and counter-current flow configuration and varying liquid flow rates. The effect of heat conduction is predominant at low flow rate and leads to very poor heat exchange within the channels in co-current and rather high in counter-current flow due to perturbation of thermal profile around the channel inlet and outlet. When flow rate increases, convective effects are predominant on heat transfer and leads to a thermal efficiency of micro-structured section between 70 and $75 \%$ for co and counter-current. This results show the great impact of heat conduction inside microstructure compact heat exchanger operated at low Reynolds number. The CFD code can be an helpful tool to optimise the geometry of microstructured plates in order to reach homogeneous thermal and flow profiles inside the channel network and to minimize poor heat transfer through the distributing and collecting sections.

\section{ACKNOWLEDGMENTS}

This study has been performed with the help of funding from International Competitiveness Cluster Lyon \& Rhône-Alpes Chemicals / Environnement (AXELERA).

\section{REFERENCES}

Favre-Marinet M., Le Person S., Bejan A. (2003) Maximum heat transfer rate density in two-dimensional minichannels and microchannels, First International Conference on Micro-channels and Mini-channels, Rochester, New York, USA, April 21-23.

Font P., Duchene V., Boyer C., Schweitzer J.M. (2006) Heat transfer in a micro-exchanger in convection and boiling mode, IMRET 9, Postdam, September 6-8.

Gamrat G., Favre-Marinet M., Asendrych D. (2004) Numerical Modeling of Heat Transfer in Rectangular Micro-channel, Microchannels and Mini-channels, Rochester, New York, USA, June 17-19.

Halbritter A., Klemm W., Löwe H., Ondruschka B., Scholz P., Schubert K. (2002) Experimental determination of heat transfer coefficients in micro heat exchangers, 6th International Conference on Micro-reaction Technology, IMRET 6, New Orleans, 11-14 march, p. 241.

Maranzana G., Perry I., Maillet D. (2004) Mini and micro-channels: influence of axial conduction in the walls, Int. J. Heat Mass Tran. 47, 3993-4004.

Niklas M., Favre-Marinet M. (2003) Pressure Losses in a Network of Triangular Micro-channels, First International Conference on Micro-channels and Mini-channels, New York, USA, April 21-23, pp. 1-8.

Peng X.F., Peterson G.P. (1996) Convective heat transfer and flow friction for water flow in micro-channel structures, Int. J. Heat Mass Tran. 39, 2599-2608.

Tonomura O., Tanaka S., Noda M., Kano M., Hasebe S., Hashimot I. (2003) CFD-based Optimal Design of Manifold in Plate-Fin Micro-devices, IMRET 7, Lausanne, September 7-10, pp. 334-336.

You H.I. (1989) Experimental determination of heat transfer coefficient between a micro-structure and fluid, Int. Commun. Heat Mass 16, 537-546.

Yu D., Warrington R., Barron R., Ameel T. (1991) An experimental and theoretical investigation of fluid flow and heat transfer in micro tubes, ASME/JSME Thermal Engineering Conference 1, 523-530.

Final manuscript received in November 2009 Published online in October 2010

Copyright (C) 2010 IFP Energies nouvelles

Permission to make digital or hard copies of part or all of this work for personal or classroom use is granted without fee provided that copies are not made or distributed for profit or commercial advantage and that copies bear this notice and the full citation on the first page. Copyrights for components of this work owned by others than IFP Energies nouvelles must be honored. Abstracting with credit is permitted. To copy otherwise, to republish, to post on servers, or to redistribute to lists, requires prior specific permission and/or a fee: Request permission from Documentation, IFP Energies nouvelles, fax.+33147527078, or revueogst@ifpenergiesnouvelles.fr. 